\title{
Characterization of Both MTBE and BTEX in the Ambient Air of Night Markets in Southern Taiwan
}

\author{
Lien-Te Hsieh ${ }^{\text {a, }}$, Hsi-Hsien Yang ${ }^{b}$, Ho-Wen Chen ${ }^{b}$ \\ ${ }^{a}$ Department of Environmental Engineering and Science, National Pingtung University of Science \\ and Technology, Nei Pu 912, Ping Tung, Taiwan \\ ${ }^{b}$ Department of Environmental Engineering and Management, Chaoyang University of Technology, \\ 168 Jifong E. Rd, Wufong, Taichung County, Taiwan
}

\begin{abstract}
To characterize concentrations of volatile organic compounds (VOCs) at the night markets in southern Taiwan, four representative night markets and one background location were selected for this study. The VOCs measured included methyl tertiary-butyl ether (MTBE) and BTEX (the acronym for benzene, toluene, ethylbenzene, and xylene). The results indicated that the measured concentrations of MTBE and BTEX were typically on the order of one to two times higher at night market level than at the background site. It is clear that the night market activities in all sampling sites affected the distribution of MTBE and BTEX. During non-night market activities, the average MTBE-BTEX ratios of Liu-Ho, Rui-Guang, Ping-Tung and Chao-Zhou were (13.9: 2.2: 10.1: 1.0: 6.1), (4.9: 3.8: 13.7: 1.0: 7.9), (10.3: 1.7: 8.2: 1.0: 3.9) and (87.4: 10: 46: 1.0:9.1), respectively. However, during the night market activities, the average MTBE-BTEX ratios shifted to (27.4: 1.9: 21.9: 1.0: 4.3), (23.1: 3.9: 16.5: 1.0: 3.2), (38.6: 6.8: 30.1: 1.0: 14.9), and (38.6: 7.8: 24.3: 1.0: 5.1), respectively.
\end{abstract}

Keywords: MTBE, BTEX, Night market, VOCs, Correlation.

\section{Introduction}

It is well known that volatile organic compounds (VOCs) and some photochemical pollutants affect ambient air quality and human health (Bolla, 1991; Kinney and Ozkaynak, 1991; Romieu et al., 1996). The pollution problem related to methyl tertiary-butyl ether (MTBE) and the possible adverse effects of exposure to benzene, toluene, ethylbenzene, $m, p$-xylene and $o$-xylene (namely, BTEX)

\footnotetext{
${ }^{*}$ Corresponding author. Tel.: +886-8-7740521; Fax: +886-8-7740256.

E-mail address: Lthsieh@mail.npust.edu.tw
} 
compounds exposure are important issues in environmental research (Lillquist et al., 1998; Hong et al., 1999; Deeb et al., 2001).

In general, MTBE is a common ingredient in gasoline owing to its excellent octane rating and low impact on air quality in large cities (US EPA, 1993; NSTC, 1997; Davidson et al., 2000; Dragos, 2000). Although MTBE is used because it reduces particulate emissions, unburnt hydrocarbons, CO, and exhaust emissions, the MTBE pollution or the possible adverse effects of exposure to it are health concerns. Moreover, BTEX are widely used in industry and exert serious adverse effects on environmental air quality (Pohl et al., 2003). In general, BTEX are frequently produced not only from industrial sources, including printing and laminating facilities, foundries, electronics, and paint manufacturing units, but also occur at hazardous waste sites (ATSDR, 2001).

During the past several decades, both MTBE and BTEX have been intensively studied in many countries (Hartle, 1993; Javelaud et al., 1998; Vainiotalo et al., 1998, 1999a, 1999b; Davenport et al., 2000; Monod et al., 2001; Lee et al., 2002; Chang et al., 2003; Guo et al., 2003). However, research of both MTBE and BTEX in different environmental matrices is still at an early stage in southern Taiwan. A few studies have been conducted for VOCs in the daytime atmosphere of southern Taiwan (Tsai et al., 2002; Hsieh and Tsai, 2003), but not for MTBE or BTEX in night markets during both daytime and at night. Therefore, a detailed and thorough environmental analysis of both MTBE and BTEX is needed to set a baseline for future research in Taiwan. In particular, two distinctive national features call for such investigation.

First, Taiwan is known for a wide variety of delicacies. People in Taiwan like to buy fresh food daily by visiting the markets and the frequency of visiting night markets in Taiwan is much higher than in western countries. Therefore, ambient air quality at night markets may be more important than that in western countries. The population density is high at the markets compared to that in other outdoor environment, especially between 16:00 and 18:00 $\mathrm{h}$ and 20:00 and 24:00 $\mathrm{h}$. The air quality during these peak hours is of concern.

Second, outdoor sources may contribute to indoor concentrations of a number of air pollutants. The effect of outdoor air on the indoor air quality of a building becomes more significant when the building is in an urban area and is close to a commercial zone or traditional market street with heavy traffic. Especially, the indoor air quality of residential housing around the night markets is affected by outside night markets. Some studies indicate that ambient air quality is closely related to indoor air quality (Li, 1994; Baek et al., 1997; Jones et al., 2000).

In this study, four night markets, including Liu-Ho, Rui-Guang, Ping-Tung and Chao-Zhou, and one background location (NPUST campus), were chosen for the MTBE and BTEX investigation. The objectives of this study are to measure and characterize the concentrations of MTBE and BTEX during market activity in southern Taiwan. In additions, meteorological conditions such as wind speed, wind direction, and temperature were also measured. These results are expected to generate useful information to evaluate the health effects of these VOCs. 


\section{Sampling sites and descriptions}

This investigation focused on the characteristics of MTBE and BTEX at night markets. It also considered the relationship between the geographical location of the markets and their VOC levels. Furthermore, it was intended that the selected night markets be representative of a certain district in southern Taiwan.

As shown in Figure 1, four sampling sites, including Liu-Ho in Kaohsiung city, Rui-Guang in Pingtung city, Ping-Tung in Pingtung city, and Chao-Zhou in Chao-Zhou town, were selected for VOC monitoring. These night markets were selected based on their representativeness of nightmarket activity in Taiwan. The four sites are also the key feature of citizens' night-market activity. In addition, for the purpose of comparison, the campus of National Pingtung University of Science and Technology (NPUST campus) was selected as the VOC background location due to low traffic and few industrial sources. Descriptions of these locations are as follows:

Liu-Ho night market: Located downtown, about 10 minutes' walk from the Kaohsiung Railway Station, with 138 pitches opening all night long. It is in a district with a high-density population. The government of Kaohsiung City established a temporary concentration area for pitches in 1962. And further in 1987, the government began practicing "pedestrian walk" (which all vehicles are banned from entering) during the business hour from 18:00 to midnight. Today this night market covers an area of about 1,500 square meters. This open-air market includes include: (1) one main shopping street; (2) some shops and stores inside buildings; and (3) many vendors along the street with pitches.

Rui-Guang night market: Located in the neighborhood of Rui-Guang Road, with hundreds of booths open at night. It is open only at night and sells seafood, barbecue meat, roast poultry, and dry goods. The market is on a main street with busy traffic, and is crowded at night. The market has only one floor, distinguishing it from the other markets. It covers an area of about 40,000 square meters. This open-air market includes: (1) many vendors along the street with pitches; (2) a few shops and stores inside buildings.

Ping-Tung night market: A traditional Chinese night market located near Ping-Tung city across from the busy Min-Sheng road. During the day, only a few customers are in the streets, while at night (during business hours) there are many traders' stalls on both sides of the streets, and the market is crowded, peaking in activity at 17:00-22:00 h. This night market covers an area of about 10,000 square meters. The predominantly open-air market includes: (1) many vendors along the street with pitches, and (2) some shops and stores inside buildings.

Chao-Zhou night market: Located in the center of Chao-Zhou Town near an urban residential area with moderate population density and low traffic. During the period of 16:00-18:00 h, there are many housewives buying food for dinner. The drainage is not good; some of the pipes are broken and a rancid odor was detected during the sampling period. This night market covers an area of about 60,000 square meters. This predominantly open-air market includes: (1) many vendors across the street with pitches, and (2) a few shop and stores inside buildings. 
National Pingtung University of Science and Technology (NPUST) campus: National Pingtung University of Science and Technology (NPUST) campus is situated in the vicinity of Lao-Pi village in Ping-Tung County with the least anthrogenic pollution and environmental impact. Usually, it is considered as a background monitoring station.

\section{Materials and methods}

\section{Sampling strategy and analytical methods}

Sampling was performed at five selected sites (Liu-Ho, Rui-Guang, Ping-Tung, Chao-Zhou, and NPUST campus) during two times of the day (7:00 a.m. -- 4:00 p.m. represent non-night market activity and 6:00 p.m. -- 12:00 p.m. represent night market activity) from July 2003 to August 2004 to clarify the characterization of VOCs in the ambient air of night markets in southern Taiwan. Sampling was carried out once in a month (non-rainy days) for a period of 14 months (July 2003 to August 2004). The sample numbers are listed in Table 1. Sampling height was $1.5 \mathrm{~m}$ for each site. In each sampling day at each sampling site, four samples (including the up-, down-, left- and rightstreams) were taken per two hours and together. The average of those four samples at the up-, down-, left- and right- stream was taken as one representative sample of the ambient air of the night market in each sampling day.

Table 1. Basic meteorological condition at four night markets and one background location.

\begin{tabular}{|c|c|c|c|c|c|c|c|c|}
\hline \multirow{3}{*}{ 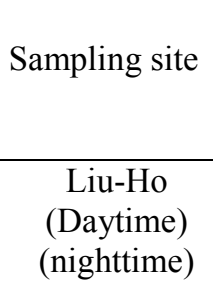 } & \multirow{2}{*}{$\begin{array}{l}\text { Sample numbers } \\
\qquad \begin{array}{c}(\mathrm{N}) \\
14\end{array}\end{array}$} & \multirow{2}{*}{$\begin{array}{c}\begin{array}{c}\text { Temp. } \\
\left({ }^{\circ} \mathrm{C}\right) \\
(\text { mean })\end{array} \\
25.5 \pm 3.2\end{array}$} & $\begin{array}{c}\text { Relative } \\
\text { Humidity } \\
(\%) \\
(\text { mean }) \\
\end{array}$ & $\begin{array}{l}\text { Atmospheric } \\
\text { pressure } \\
(\mathrm{mmHg}) \\
(\text { mean })\end{array}$ & \multicolumn{2}{|c|}{$\begin{array}{l}\text { Wind speed } \\
\qquad(\mathrm{m} / \mathrm{s}) \\
(\text { mean })\end{array}$} & \multicolumn{2}{|c|}{$\begin{array}{l}\text { Sunlight strength } \\
\text { (Lux) } \\
\text { (mean) }\end{array}$} \\
\hline & & & $55.2 \pm 2.1$ & $761.1 \pm 3.0$ & $1.5 \pm$ & 0.5 & $4452.0 \pm$ & 3352.5 \\
\hline & 14 & $25.5 \pm 3.2$ & $55.2 \pm 2.1$ & $761.1 \pm 3.0$ & $1.1 \pm$ & 0.2 & 116.0 & 63.1 \\
\hline $\begin{array}{l}\text { Rui-Guang } \\
\text { (Daytime) }\end{array}$ & 14 & $27.1 \pm 2.0$ & $50.3 \pm 1.7$ & $765.5 \pm 1.7$ & $0.9 \pm$ & 0.5 & 3326.1 & 2875.7 \\
\hline (nighttime) & 14 & $25.3 \pm 1.6$ & $54.6 \pm 3.8$ & $764.2 \pm 3.9$ & $0.1 \pm$ & 0.0 & 120.7 & 38.1 \\
\hline $\begin{array}{l}\text { Ping-Tung } \\
\text { (Daytime) }\end{array}$ & 14 & 27.2 & $56.6 \pm 4.0$ & $762.4 \pm 5.0$ & $0.4 \pm$ & 0.4 & 2343.3 & 1539.7 \\
\hline (nighttime) & 14 & $27.2 \pm 2.7$ & $56.6 \pm 4.0$ & $762.4 \pm 5.0$ & $0.3 \pm$ & 0.1 & 150.7 & 13.1 \\
\hline $\begin{array}{l}\text { Chao-Zhou } \\
\text { (Daytime) }\end{array}$ & 14 & $28.3 \pm 1.9$ & $56.6 \pm 5.0$ & $763.6 \pm 1.4$ & $1.0 \pm$ & 0.6 & $11842.6 \pm$ & 3029.7 \\
\hline (nighttime) & 14 & $27.1 \pm 1.0$ & $61.5 \pm 2.7$ & $766.0 \pm 2.9$ & $0.1 \pm$ & 0.0 & 51.3 & 30.4 \\
\hline $\begin{array}{c}\text { NPUST } \\
\text { Campus } \\
\text { (Daytime) }\end{array}$ & 13 & $22.4 \pm 2.5$ & $59.7 \pm 8.7$ & $765.6 \pm 2.1$ & $0.3 \pm$ & 0.3 & $17604.3 \pm$ & 2710.4 \\
\hline (nighttime) & 13 & $20.2 \pm 1.5$ & $64.4 \pm 6.3$ & $766.1 \pm 1.3$ & $0.4 \pm$ & 0.0 & 0.0 & 0.0 \\
\hline
\end{tabular}




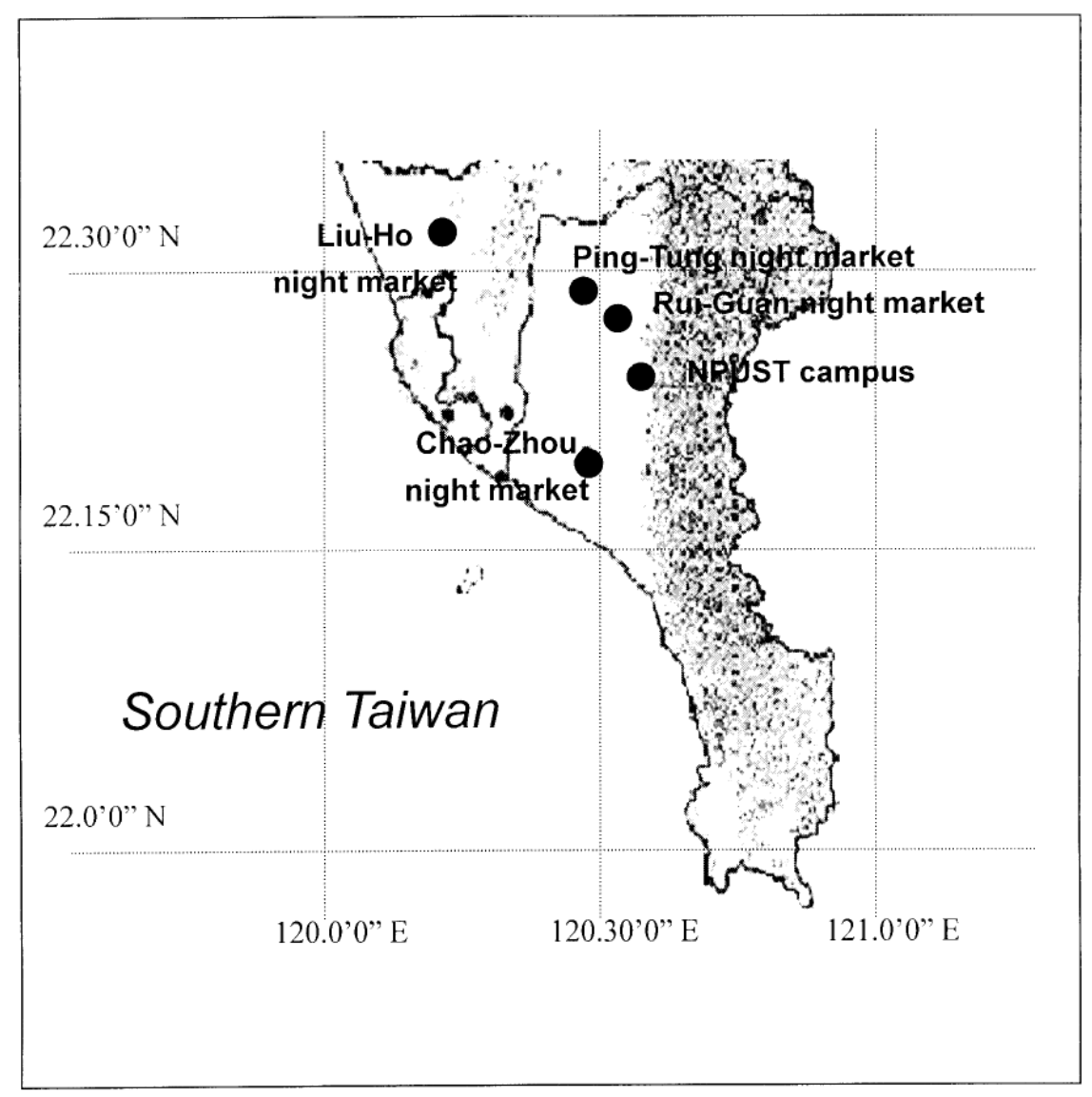

Figure 1. Sampling location in southern Taiwan.

For each collected sample, MTBE and BTEX were analyzed by gas chromatography with a flame ionization detector (GC/FID; Agilent Technologies, 6890N Network GC System) using NIOSH Method 1615 (NIOSH, 1994). The stock solution was prepared using VOCs Mix 2 (Supelco, 4-8167, Bellefonte, PA). The established calibration curves for the six investigated VOCs were found to have R-square-values $>0.996$. Three replicate analyses were performed on each of the three samples with known specified concentrations, and the relative standard deviations (RSDs) thus obtained were used to assess the accuracy of the method.

\section{Quality control}

Background contamination was monitored by using operational blanks (unexposed sampling tubes) processed simultaneously with field samples. The field blanks were exposed when the field sampling tube was opened to remove and replace samples. Background contamination was accounted for by subtracting field blank values from the concentrations. Field blank values were low, usually below or around the method detection limits. In this study, the background contamination is insignificant. When investigating VOC concentrations by using adsorption charcoal sampling tube, the breakthrough percentage of the second adsorption tube is critical. In this study, if the level of the 
second adsorption tube is higher than $10 \%$ of the level of the first adsorption tube, then such a sample should be recollected by an adjustment in sampling volume.

At least $10 \%$ of the samples are analyzed in spiking with a known amount of compound to calculate recovery efficiencies. The analysis procedure for the recovery test is the same as that described for the field samples. The desorption efficiencies of target species were $95.5 \%, 92.5 \%$, 95.4\%, 93.1\%, 93.2\% and 91.7\% for MTBE, benzene, toluene, ethylbenzene, and $\mathrm{m} / \mathrm{p}$-xylene and $o$ xylene, respectively. The range of desorption efficiency test varies between $85 \%$ and $97 \%$ and the RSD is smaller than $10 \%$.

The analysis of the same standard solution was repeated several times. The reproducibility test demonstrated the stability of the instruments. The RSD varied between $95 \%$ and $105 \%$, and the mean relative deviation is smaller than 5\%. Detection limit was used to determine the lowest concentration level that can be detected to be statistically different from a blank. Method detection limit (MDL) was determined from selected the concentration slightly higher than the low concentration of the standard line, repeated this concentration for 12 times to estimate the standard deviation (S). The MDL was equally to be $(3 \times S)$. The analytical results displayed that the MDLs for the six VOC compounds of the MTBE, benzene, toluene, ethylbenzene, and $m / p$-xylene and $o$-xylene were 0.030 , $0.0092,0.025,0.020,0.0097$ and $0.0098 \mu \mathrm{g}$, respectively.

\section{Results and discussion}

\section{MTBE and BTEX concentrations}

Table 1 shows the sample number and basic meteorological condition at four night markets and one background location during the sampling periods. The average temperature at the four markets ranged from 20.2 to $28.3{ }^{\circ} \mathrm{C}$. The average relative humidity (\%) at the four markets ranged from 50.3 to $64.4 \%$. These locations are in a semi-tropical region and are affected by the alternate northeastern and southwestern seasonal currents.

Tables 2 and 3 list the descriptive statistics of the MTBE and BTEX measured during non-night and night market activities periods, respectively, at the four different night markets and a background location. Table 2 shows, during non-night market activities periods, higher MTBE and toluene concentrations in all sampling sites, followed by $m, p$-xylene, benzene, ethylbenzene and finally, $o$ xylene. With similar tendency, table 3 presents a higher MTBE concentration in all sampling sites during night market activities periods, followed by toluene, $m, p$-xylene, benzene, ethylbenzene and finally, $o$-xylene. It is clear that maximum toluene concentrations measured in all sampling sites, during either non-night or night market activities periods, do not exceed world-wide safety norms as recommended by NIOSH and OSHA, health guidelines (NIOSH, 1988; NIOSH/OSHA/DOE health guidelines, 2000). 
To understand the difference between non-night and night market activities periods, we make a comparison between Table 2 and Table 3. For MTBE, MTBE mean concentrations in the four sampling sites were all higher during night market activities periods than during non-night market activities periods. The ratios of night/non-night for MTBE were about 1.4, 21.3, 1.3 and 3.7 at LiuHo, Rui-Guang, Ping-Tung and Chao-Zhou, respectively. At NPUST campus, such ratio can not estimate due to the measured level under the detection limitation during non-night market activities periods. In fact, even at night time, the MTBE mean concentration at NPUST campus as background base was lower than any of the four sampling sites in this study.

For benzene, benzene mean concentrations in the four sampling sites were all higher during night market activities periods than during non-night market activities periods. The ratios of night/nonnight for benzene were approximately 1.6, 4.6, 1.3 and 6.5 at Liu-Ho, Rui-Guang, Ping-Tung and Chao-Zhou, respectively. At NPUST campus, such ratio can not estimate due to one of the measured levels under the detection limitation.

For toluene, toluene mean concentrations in the four sampling sites were all higher during night market activities periods than during non-night market activities periods. The ratios of night/nonnight for toluene were about 4.0, 5.5, 1.2, 4.4 and 5.4 at Liu-Ho, Rui-Guang, Ping-Tung, Chao-Zhou and NPUST campus, respectively.

Table 2. Descriptive statistics of the MTBE and BTEX measured at four night markets and a background location during non-night market activity periods.

\begin{tabular}{cccccc}
\hline Concentration $\left(\mu \mathrm{g} / \mathrm{m}^{3}\right)$ & Mean & Median & S.D. & Min. & Max. \\
\hline MTBE & & & & & \\
Liu-Ho & 31.7 & 26.5 & 21.2 & ND & 63.7 \\
Rui-Guang & 7.33 & 0.00 & 20.72 & ND & 58.62 \\
Ping-Tung & 114.8 & 57.1 & 125.2 & 20.8 & 406.5 \\
Chao-Zhou & 28.63 & 21.19 & 38.19 & ND & 118.94 \\
NPUST campus & ND & ND & ND & ND & ND \\
\hline Benzene & & & & & \\
Liu-Ho & 4.97 & 4.67 & 4.55 & ND & 11.63 \\
Rui-Guang & 5.64 & 3.63 & 6.83 & ND & 19.56 \\
Ping-Tung & 19.36 & 8.97 & 20.88 & 4.05 & 68.46 \\
Chao-Zhou & 3.29 & 2.20 & 4.20 & ND & 11.79 \\
NPUST campus & ND & ND & ND & ND & ND \\
\hline Toluene & & & & & \\
Liu-Ho & 22.91 & 16.27 & 19.44 & ND & 54.41 \\
Rui-Guang & 20.22 & 14.51 & 13.84 & 7.13 & 45.80 \\
Ping-Tung & 91.74 & 27.85 & 111.41 & 6.38 & 348.27 \\
Chao-Zhou & 15.05 & 13.15 & 12.84 & 1.17 & 35.24 \\
NPUST campus & 1.27 & 1.07 & 1.40 & ND & 3.43 \\
\hline
\end{tabular}


Table 2. (continued)

\begin{tabular}{cccccc}
\hline Ethylbenzene & & & & \\
Liu-Ho & 2.27 & 0.69 & 3.22 & ND & 7.80 \\
Rui-Guang & 1.48 & 0.20 & 2.35 & ND & 6.13 \\
Ping-Tung & 11.18 & 4.78 & 14.59 & ND & 45.60 \\
Chao-Zhou & 0.33 & 0.00 & 0.93 & ND & 2.62 \\
NPUST campus & ND & ND & ND & ND & ND \\
\hline M,p-Xylene & & & & 3.71 & 28.92 \\
Liu-Ho & 12.98 & 9.60 & 9.23 & 2.31 & 21.60 \\
Rui-Guang & 10.81 & 11.05 & 7.04 & 8.30 & 139.67 \\
Ping-Tung & 39.98 & 21.15 & 41.82 & 0.85 & 6.82 \\
Chao-Zhou & 2.84 & 2.18 & 2.19 & ND & 17.48 \\
NPUST campus & 9.06 & 13.88 & 8.55 & & \\
\hline o-Xylene & & & & ND & 2.68 \\
Liu-Ho & 0.88 & 0.63 & 0.87 & ND & 2.39 \\
Rui-Guang & 0.83 & 0.59 & 0.84 & 0.55 & 12.37 \\
Ping-Tung & 4.00 & 2.09 & 4.08 & ND & 0.62 \\
Chao-Zhou & 0.15 & 0.00 & 0.28 & ND & ND \\
\hline NPUST campus & ND & ND & ND & & \\
\hline
\end{tabular}

For ethylbenzene, ethylbenzene mean concentrations at the sampling sites (except for at Ping-Tung) were higher during night market activities periods than during non-night market activities periods. The ratios of night/non-night for ethylbenzene were approximately 1.8, 4.6, 0.3 and 8.5 at Liu-Ho, Rui-Guang, Ping-Tung and Chao-Zhou, respectively. At the NPUST campus, such ratios cannot be estimated because both of the measured levels were under the detection limit. However, it is worth noting that the mean concentrations of ethylbenzene during non-night market activity periods was about 2.9 times higher than those during night market activities periods. This result could be explained by the fact that at the Ping-Tung sampling site, much heavy traffic loading (i.e., city-buses and hauled-trucks) during day time compared to that during night time. Therefore, the ethylbenzene from such heavy traffic source was a great contribution to Ping-Tung sampling site during day time compared to that during night time.

For $m, p$-xylene, mean concentrations at the four sampling sites were higher during night market activity periods than during non-night periods. The ratios of night/non-night for $m, p$-xylene were about 1.3, 1.7, 1.3, 4.0 and 1.7 at Liu-Ho, Rui-Guang, Ping-Tung, Chao-Zhou, and the NPUST campus, respectively. For $o$-xylene, mean concentrations at the four sampling sites were all higher during night market activities periods than during non-night market activities periods. The ratios of night/non-night for $o$-xylene were about 1.4, 4.0, 1.2 and 17.9 at Liu-Ho, Rui-Guang, Ping-Tung and Chao-Zhou, respectively. At the NPUST campus, such ratios cannot be estimated because one of the measured levels was under the detection limit. 
Table 3. Descriptive statistics of the MTBE and BTEX measured at four night markets and a background location during night market activity periods.

\begin{tabular}{|c|c|c|c|c|c|}
\hline Concentration $\left(\mu \mathrm{g} / \mathrm{m}^{3}\right)$ & Mean & Median & S.D. & Min. & Max. \\
\hline \multicolumn{6}{|l|}{$M T B E$} \\
\hline Liu-Ho & 45.74 & 47.18 & 20.63 & 22.13 & 78.83 \\
\hline Rui-Guang & 155.92 & 136.89 & 76.48 & 51.72 & 247.70 \\
\hline Ping-Tung & 146.86 & 96.31 & 113.38 & 13.28 & 303.45 \\
\hline Chao-Zhou & 105.70 & 97.18 & 46.33 & 42.21 & 171.70 \\
\hline NPUST campus & 12.20 & 11.57 & 13.08 & ND & 31.09 \\
\hline \multicolumn{6}{|l|}{ Benzene } \\
\hline Liu-Ho & 7.89 & 8.92 & 2.91 & 4.04 & 11.92 \\
\hline Rui-Guang & 26.20 & 22.71 & 12.63 & 8.93 & 43.12 \\
\hline Ping-Tung & 25.79 & 15.84 & 20.56 & ND & 54.18 \\
\hline Chao-Zhou & 21.47 & 19.45 & 11.12 & 7.47 & 36.91 \\
\hline NPUST campus & 1.57 & 0.00 & 4.16 & ND & 11.01 \\
\hline \multicolumn{6}{|l|}{ Toluene } \\
\hline Liu-Ho & 91.74 & 27.85 & 111.41 & 6.38 & 348.27 \\
\hline Rui-Guang & 111.34 & 101.59 & 59.84 & 28.88 & 191.15 \\
\hline Ping-Tung & 114.65 & 65.88 & 90.89 & 0.78 & 229.84 \\
\hline Chao-Zhou & 66.64 & 54.44 & 39.81 & 16.15 & 127.44 \\
\hline NPUST campus & 6.80 & 5.57 & 4.28 & 1.42 & 13.23 \\
\hline \multicolumn{6}{|l|}{ Ethylbenzene } \\
\hline Liu-Ho & 4.19 & 5.57 & 2.92 & ND & 7.55 \\
\hline Rui-Guang & 6.76 & 5.24 & 4.94 & 1.96 & 14.70 \\
\hline Ping-Tung & 3.80 & 2.49 & 3.11 & ND & 8.44 \\
\hline Chao-Zhou & 2.74 & 2.41 & 1.29 & 1.11 & 4.72 \\
\hline NPUST campus & ND & ND & ND & ND & ND \\
\hline \multicolumn{6}{|l|}{ M,p-Xylene } \\
\hline Liu-Ho & 16.97 & 14.47 & 8.06 & 5.12 & 27.22 \\
\hline Rui-Guang & 18.49 & 7.18 & 17.67 & 3.83 & 44.18 \\
\hline Ping-Tung & 51.88 & 32.80 & 39.90 & 1.96 & 106.28 \\
\hline Chao-Zhou & 11.32 & 5.80 & 9.01 & 2.80 & 24.07 \\
\hline NPUST campus & 15.56 & 18.18 & 7.18 & ND & 20.53 \\
\hline \multicolumn{6}{|l|}{ o-Xylene } \\
\hline Liu-Ho & 1.21 & 1.48 & 0.65 & ND & 2.04 \\
\hline Rui-Guang & 3.33 & 3.25 & 1.50 & 1.34 & 5.28 \\
\hline Ping-Tung & 4.62 & 2.76 & 3.74 & ND & 10.99 \\
\hline Chao-Zhou & 2.69 & 2.36 & 1.27 & 1.03 & 4.80 \\
\hline NPUST campus & ND & ND & ND & ND & ND \\
\hline
\end{tabular}


The ratios of non-night/night at Ping-Tung site (1.3, 1.3, 1.2, 0.3, 1.3 and 1.2 for MTBE, benzene, toluene, ethylbenzene, and $m, p$-xylene and $o$-xylene, respectively) were lower than those at others sites. Considering that the Ping-Tung site is near Ping-Tung city with heavy urban traffic (i.e., gasoline-powered vehicles), these inconsistencies might be worth further discussion. Vehicle driving speeds at the night market's road were much slower than those at urban traffic main arteries. According to a laboratory study conducted by Sigsby et al. (1987), it was observed that the concentrations of toluene, ethylbenzene, and xylene in vehicle exhaust decreased as the driving speeds increased. For this reason, the VOC content for Ping-Tung sampling site was mainly contributed by vehicle exhaust dispersion near Ping-Tung City. Moreover, the measured concentrations of MTBE and BTEX were typically on the order of one to two times higher at night market level than at the background site (NPUST campus) due to proximity to emission sources and the market activities; background concentrations were probably lowered by rare existence of VOCs sources, dispersive dilution and mixing, and photochemical reactions.

Finally, the results obtained in this study compared to those from other studies conducted on different environments show that the exposure of VOC levels in the four sites during night market activities were much lower than those environments associated with gasoline vapor emission, such as the exposure levels for service stations (Hartle, 1993), petroleum refinery (Lillquist and Zeigle, 1998) and dispatch tank truck (Vainiotalo and Ruonakangas, 1999b), but were quite comparable with those associated vehicle exhaust, such as the exposure levels for car driver (Joop and Henk, 1995), for traffic police officer (Jo and Song, 2001) and pedestrians (Chan et al., 1991). Moreover, although no time-weighted-average threshold limit value (TLV-TWA) has been suggested for MTBE, all BTEX concentrations during night market activities obtained from this study were still lower than the current TLVs-TWA for benzene, toluene, ethylbenzene, and xylene $=0.5,100,50$, and $100 \mathrm{ppm}$, respectively (ACGIH).

\section{MTBE and BTEX correlations during non-night/night market activities}

As listed in Tables 4 and 5, MTBE and BTEX correlations were assessed at the all five sampling locations during non-night and night market activities periods, respectively. During non non-night market activities periods, high MTBE and BTEX correlations were noted at the Liu-Ho and PingTung; comparatively, median or low MTBE and BTEX correlations were noted at Rui-Guang and Chao-Zhou (Table 4.). During night market activity periods, high MTBE and BTEX correlations were noted only in the Ping-Tung (Table 5.). However, in three other night markets (i.e., Liu-Ho, Rui-Guang and Chao-Zhou), low or negative MTBE and BTEX correlations were observed during night market activity periods. The correlation between MTBE and toluene, ethylbenzene and $m, p$ xylene is not consistent. Notably, good correlations between MTBE and benzene-tolueneethylbenzene-o-xylene, and poor correlations between $m, p$-xylene and benzene-tolueneethylbenzene were observed at Chao-Zhou (Table 5.). Comparing Table 4 with Table 5, it is noted 
that at Liu-Ho the significance of correlation between toluene and MTBE-BEX decreased due to the occurrence of the night market activities; however, at Chao-Zhou the correlation between toluene and MTBE-o-xylene increased. At this stage, whether this difference was due to the intrinsic differences in market activities warrants further investigation.

Regarding the significance of correlation at the background site, it is not surprising that the MTBE concentration at the NPUST campus does not show a high or median correlation with most BTEX concentrations, indicating that the rural background has different sources compared to all night market sites. This result also implied that appliance type (gas, electric, and microwave), cooking method (frying, baking, broiling, range-top burner, oven), food type (variety of foods cooked), cooking vessel (pan material, lids) and exposure reduction methods (exhaust fan, hood shields) influence the decrease in air quality during night market activities.

Table 4. Summary of MTBE and BTEX correlation coefficients (R) in different sampling locations during non-night market activity periods.

\begin{tabular}{|c|c|c|c|c|c|c|}
\hline & MTBE & Benzene & Toluene & Ethylbenzene & $m, p$-Xylene & $o$-Xylene \\
\hline \multicolumn{7}{|l|}{ Liu-Ho } \\
\hline MTBE & 1.00 & & & & & \\
\hline Benzene & $0.92^{* *}$ & 1.00 & & & & \\
\hline Toluene & $0.95^{* *}$ & $0.97^{* *}$ & 1.00 & & & \\
\hline Ethylbenzene & $0.92^{* *}$ & $0.90^{* *}$ & $0.94^{* *}$ & 1.00 & & \\
\hline$m, p$-Xylene & $0.95^{* *}$ & $0.91^{* *}$ & $0.93^{* *}$ & $0.97^{* *}$ & 1.00 & \\
\hline$o$-Xylene & $0.92^{* *}$ & $0.91^{* *}$ & $0.94^{* *}$ & $0.95^{* *}$ & $0.94^{* *}$ & 1.00 \\
\hline \multicolumn{7}{|l|}{ Rui-Guang } \\
\hline MTBE & 1.00 & & & & & \\
\hline Benzene & $0.82^{*}$ & 1.00 & & & & \\
\hline Toluene & 0.28 & $0.69^{*}$ & 1.00 & & & \\
\hline Ethylbenzene & -0.05 & 0.47 & $0.91^{* *}$ & 1.00 & & \\
\hline$m, p$-Xylene & -0.44 & 0.04 & 0.53 & $0.78^{*}$ & 1.00 & \\
\hline$o$-Xylene & $0.75^{*}$ & $0.96^{* *}$ & $0.75^{*}$ & 0.57 & 0.19 & 1.00 \\
\hline \multicolumn{7}{|l|}{ Ping-Tung } \\
\hline MTBE & 1.00 & & & & & \\
\hline Benzene & $1.00^{* *}$ & 1.00 & & & & \\
\hline Toluene & $1.00^{* *}$ & $1.00^{* *}$ & 1.00 & & & \\
\hline Ethylbenzene & $1.00^{* *}$ & $1.00^{* *}$ & $0.99^{* *}$ & 1.00 & & \\
\hline$m, p$-Xylene & $1.00^{* *}$ & $0.99^{* *}$ & $0.99^{* *}$ & $0.99^{* *}$ & 1.00 & \\
\hline$o$-Xylene & 0.80 & $0.81^{*}$ & $0.80^{*}$ & $0.82^{*}$ & $0.80^{*}$ & 1.00 \\
\hline \multicolumn{7}{|l|}{ Chao-Zhou } \\
\hline MTBE & 1.00 & & & & & \\
\hline
\end{tabular}


Table 4. (continued)

\begin{tabular}{ccccccc} 
Benzene & $0.77^{*}$ & 1.00 & & & & \\
Toluene & 0.47 & $0.79^{*}$ & 1.00 & & & \\
Ethylbenzene & $0.96^{* *}$ & $0.82^{* *}$ & 0.56 & 1.00 & & \\
$m, p$-Xylene & 0.13 & -0.25 & -0.29 & 0.08 & 1.00 & \\
$o$-Xylene & -0.10 & -0.07 & -0.02 & -0.22 & 0.07 & 1.00 \\
\hline NPUST campus & & & & & & \\
MTBE & 1.00 & & & & & \\
Benzene & --- & 1.00 & & & & \\
Toluene & --- & --- & 1.00 & & & \\
Ethylbenzene & --- & --- & --- & 1.00 & & \\
$m, p$-Xylene & --- & --- & 0.17 & --- & 1.00 & \\
$o$-Xylene & --- & --- & --- & -- & - & 1.00 \\
\hline
\end{tabular}

** correlation (0.01, 2-tailed); * correlation (0.05, 2-tailed).

\section{Shift in distribution and MTBE-BTEX ratio of VOCs}

It is interesting to note the shift in distribution of VOCs due to the night market activities in southern Taiwan, since ambient air quality at night markets in Taiwan may be more important than that in western countries. Figure 2 shows those changes of distribution of both MTBE and BTEX from non-night market activities to night market activities at the four sampling sites. It is clear that the night market activities in all sampling sites did affect the distribution of MTBE and BTEX. At Ping-tung (Figure 2C), we can distinguish market activity periods by the fractions. This similarity is relevant to its location near Min-Sheng road.

Average MTBE-BTEX ratios were also calculated to compare the VOC emissions among the four sampling sites. During non-night market activities, the average MTBE-BTEX ratios of Liu-Ho, RuiGuang, Ping-Tung, and Chao-Zhou were (13.9: 2.2: 10.1: 1.0: 6.1), (4.9: 3.8: 13.7: 1.0: 7.9), (10.3: 1.7: 8.2: 1.0: 3.9) and (87.4: 10: 46: 1.0: 9.1), respectively. However, during the night market activities, the average MTBE-BTEX ratios of Liu-Ho, Rui-Guang, Ping-Tung, and Chao-Zhou were shifted to (27.4: 1.9: 21.9: 1.0: 4.3), (23.1: 3.9: 16.5: 1.0:3.2), (38.6: 6.8: 30.1: 1.0: 14.9) and (38.6: 7.8: 24.3: 1.0: 5.1), respectively. It is interesting that those measured in the Chinese night market sites are different from other studies. For example, in the atmosphere of Hong Kong, the BTEX ratios in Mong Kok, Kwai Chung, Yuen Long, Causeway Bay and Hok Tsui were (1.3:11.5:1.0:2.8), (1.0:10.6:2.1:3.1), (1.4:6.1:1.0:2.6), (1.0:6.9:1.3:2.1) and (3.3:6.3:1.3:1.0), respectively (Lee et al., 2002). Different ratios of BTEX were also reported in other studies on vehicle exhaust, such as (3:5:1:3), (3:14:1:4), (4:11:1:3) and (7:11:1:3) in the Lincoln Tunnel (USA), at Newark, Elizabeth and Camden, respectively (Harkov et al., 1983). At this stage, whether this difference was mainly due to the intrinsic difference on emission sources warrants the need for further investigation. 
Table 5. Summary of MTBE and BTEX correlation coefficients (R) in different sampling locations during night market activity periods.

\begin{tabular}{|c|c|c|c|c|c|c|}
\hline & MTBE & Benzene & Toluene & Ethylbenzene & $m, p$-Xylene & $o$-Xylene \\
\hline \multicolumn{7}{|l|}{ Liu-Ho } \\
\hline MTBE & 1.00 & & & & & \\
\hline Benzene & $0.94^{* *}$ & 1.00 & & & & \\
\hline Toluene & 0.32 & 0.27 & 1.00 & & & \\
\hline Ethylbenzene & $0.94^{* *}$ & $0.98^{* *}$ & 0.39 & 1.00 & & \\
\hline$m, p$-Xylene & $0.85^{*}$ & $0.87^{* *}$ & 0.55 & $0.94^{* *}$ & 1.00 & \\
\hline$o$-Xylene & $0.90^{* *}$ & $0.94^{* *}$ & 0.39 & $0.96^{* *}$ & $0.92^{* *}$ & 1.00 \\
\hline \multicolumn{7}{|l|}{ Rui-Guang } \\
\hline MTBE & 1.00 & & & & & \\
\hline Benzene & $0.98^{* *}$ & 1.00 & & & & \\
\hline Toluene & $0.98^{* *}$ & $0.99^{* *}$ & 1.00 & & & \\
\hline Ethylbenzene & -0.12 & -0.15 & -0.03 & 1.00 & & \\
\hline$m, p$-Xylene & -0.40 & -0.40 & -0.30 & $0.95^{* *}$ & 1.00 & \\
\hline$o$-Xylene & $0.90^{* *}$ & $0.84^{*}$ & $0.89^{* *}$ & 0.19 & -0.09 & 1.00 \\
\hline \multicolumn{7}{|l|}{ Ping-Tung } \\
\hline MTBE & 1.00 & & & & & \\
\hline Benzene & $0.99^{* *}$ & 1.00 & & & & \\
\hline Toluene & $0.99^{* *}$ & $0.99^{* *}$ & 1.00 & & & \\
\hline Ethylbenzene & $1.00^{* *}$ & $1.00^{* *}$ & $0.99^{* *}$ & 1.00 & & \\
\hline$m, p$-Xylene & $0.99^{* *}$ & $0.98^{* *}$ & $0.99^{* *}$ & $0.98^{* *}$ & 1.00 & \\
\hline$o$-Xylene & $0.99^{* *}$ & $0.99^{* *}$ & $0.98^{* *}$ & $0.99^{* *}$ & $0.98^{* *}$ & 1.00 \\
\hline \multicolumn{7}{|l|}{ Chao-Zhou } \\
\hline MTBE & 1.00 & & & & & \\
\hline Benzene & $0.95^{* *}$ & 1.00 & & & & \\
\hline Toluene & $0.98^{* *}$ & $0.96^{* *}$ & 1.00 & & & \\
\hline Ethylbenzene & $0.98^{* *}$ & $0.96^{* *}$ & 1.00 & 1.00 & & \\
\hline$m, p$-Xylene & -0.44 & -0.65 & -0.49 & -0.47 & 1.00 & \\
\hline$o$-Xylene & $0.95^{* *}$ & $0.92^{* *}$ & $0.99^{* *}$ & $0.99^{* *}$ & -0.37 & 1.00 \\
\hline \multicolumn{7}{|c|}{ NPUST campus } \\
\hline MTBE & 1.00 & & & & & \\
\hline Benzene & 0.13 & 1.00 & & & & \\
\hline Toluene & 0.11 & -0.25 & 1.00 & & & \\
\hline Ethylbenzene & --- & --- & --- & 1.00 & & \\
\hline$m, p$-Xylene & 0.19 & 0.26 & 0.23 & --- & 1.00 & \\
\hline$o$-Xylene & --- & --- & --- & --- & --- & 1.00 \\
\hline
\end{tabular}

** correlation $(0.01,2$-tailed); * correlation $(0.05,2$-tailed $)$. 
In addition, this shift phenomenon is not associated with the difference of photochemical reaction between non-night market activity (daytime) and night market activity (nighttime). Photochemical reactions may prevent some of the traffic-emitted VOCs to contribute to the ambient air in the market sites, but as the distance from an elevated road to the market is only a few hundred meters, hence, we should not expect significant discrimination between species based on their reaction rates. Even for $m$-xylene and $p$-xylene, which have high photochemical reaction rates, the transportation time is expected to be considerably shorter than their half-lifes so that no effect of photochemical degradation should be considered.
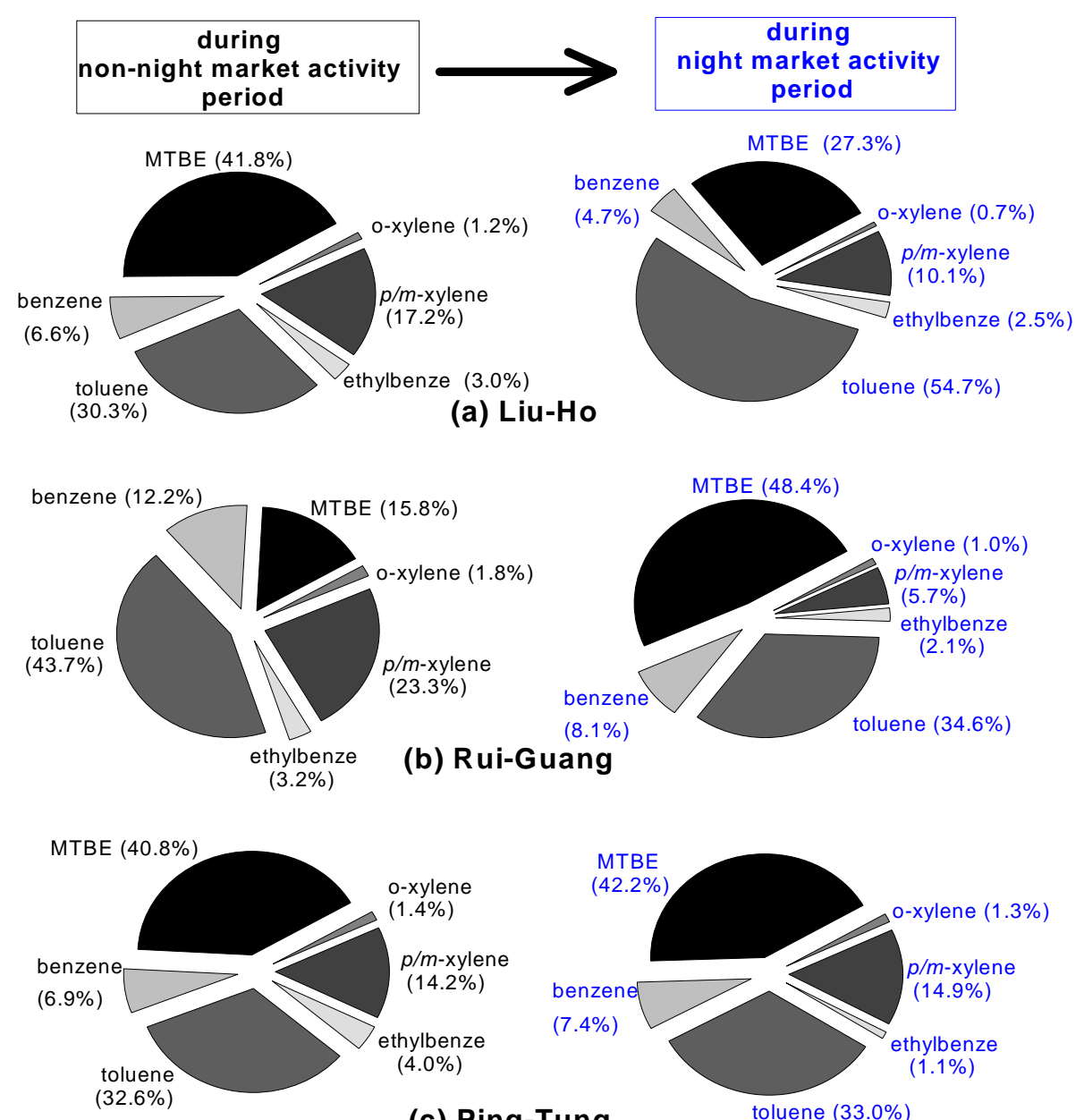

(c) Ping-Tung

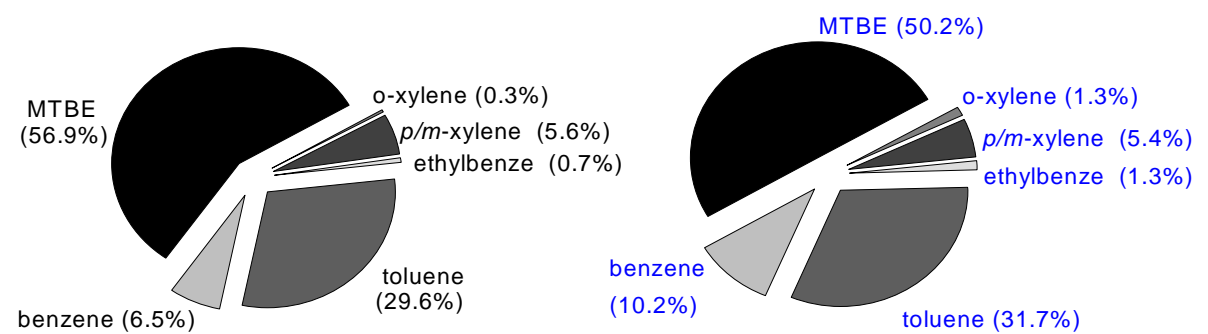

(d) Chao-Zhou

Figure 2. The changes of distribution of both MTBE and BTEX from non-night market activities to night market activities at the four sampling sites. 


\section{Conclusions}

This study has provided important information on the impact of night market activities on ambient air concentrations and exposure in traditional night markets. The data provide a better understanding of the magnitude and variability of emissions due to night market activities. Results show that a higher MTBE concentration in all sampling sites during night market activity periods, followed by toluene, $m$, $p$-xylene, benzene, ethylbenzene, and $o$-xylene. All BTEX concentrations during night market activities obtained from this study were still lower than the current TLVs-TWA for benzene, toluene, ethylbenzene, and xylene. During non-night market activities, the average MTBE-BTEX ratios of Liu-Ho, Rui-Guang, Ping-Tung, and Chao-Zhou were (13.9: 2.2: 10.1: 1.0: 6.1), (4.9: 3.8: 13.7: 1.0: 7.9), (10.3: 1.7: 8.2: 1.0: 3.9) and (87.4: 10: 46: 1.0: 9.1), respectively. However, during the night market activities, the average MTBE-BTEX ratios of Liu-Ho, Rui-Guang, Ping-Tung and Chao-Zhou were shifted to (27.4: 1.9: 21.9: 1.0: 4.3), (23.1: 3.9: 16.5: 1.0: 3.2), (38.6: 6.8: 30.1: 1.0: 14.9) and (38.6: $7.8: 24.3: 1.0: 5.1)$, respectively.

\section{Acknowledgments}

This work was partly financed by the National Science Council of the Republic of China, Taiwan, under Contract No. NSC 92-2211-E-020-004. Sampling assistance from Miss Mei-Ling Li is also greatly appreciated.

\section{References}

ATSDR, 2001. Interaction profile for benzene, ethylbenzene, toluene, and xylenes (BTEX) (draft for public comments). Atlanta: Agency for Toxic Substances and Disease Registry, US Department of Health and Human Services.

Baek, S. O., Kim, Y. S. and Perry, R. (1997), Indoor air quality in homes, offices and restaurants in Korean urban areas-indoor/outdoor relationships. Atmos. Environ. 31: 529-544.

Bolla K. (1991), Neuropsychological assessment for detecting adverse effects of volatile organic compounds on the central nervous system. Environ. Health Persp. 95: 93-98.

Chan, C.C., Ozkaynak, H., Spengler, J. D. and Sheldon, L. (1991), Driver exposure to volatile organic compounds, $\mathrm{CO}$, ozone and $\mathrm{NO}_{2}$ under different driving conditions. Environ. Sci. Technol. 25: 964-972.

Chang, C. C., Lo, S. J., Lo, J. G. and Wang, J. L. (2003), Analysis of methyl tert-butyl ether in the atmosphere and implications as an exclusive indicator of automobile exhaust. Atmos. Environ. 37: 4747-4755.

Davenport, A. C., Glynn, T. J. and Rhambarose, H. (2000), Coast guard exposure to gasoline, MTBE, and benzene vapors during inspection of tank barges. Am. Ind. Hyg. Assoc. J. 61: 865-872. 
Davidson, J. M. and Creek, D. N. (2000), Using the Gasoline Additive MTBE in Forensic Environmental Investigations. Environ. Fore. 1: 31-36.

Deeb, R. A., Hu, H. Y., Hanson, J. R., Scow, K. M. and Alvarez-Cohen, L. (2001), Substrate Interactions in BTEX and MTBE Mixtures by an MTBE-Degrading Isolate. Environ. Sci. Technol. 35: $312-317$.

Dragos, D. (2000), Comparison of the Properties and Behavior of MTBE and the Fuel Oxygenates TAME, ETBE, DIPE, TBA, and Ethanol. National Groundwater Association, San Francisco, March 17.

Guo, H., Lee, S. C., Li, W. M. and Cao, J. J. (2003), Source characterization of BTEX in indoor microenvironments in Hong Kong. Atmos. Environ. 37: 73-82

Hartle, R. (1993), Exposure to methyl tert-butyl ether and benzene among service station attendants and operators. Environ. Health Persp. 101 (Suppl. 6): 23-26.

Hong, J. Y., Wang, Y. Y., Bondoc, F. Y., Yang, C. S., Gonzalez, F. J., Pan, Z., Cokonis, C. D., Hu, W. Y. and Bao, Z. (1999), Metabolism of methyl tert-butyl ether and other gasoline ethers in mouse liver microsomes lacking cytochrome P450 2E1. Toxicol. Lett. 105: 83-88.

Hsieh, C. C. and Tsai, J. H. (2003), VOC concentration characteristics in Southern Taiwan. Chemosphere, 50: 545-556.

Javelaud, B., Vian, L., Molle, R., Allain, P. and Allemand, B. (1998), Benzene exposure in car mechanics and road tanker drivers. International Archives of Occupational and Environmental Health 71: 277-283.

Jones, N. C., Thornton, C. A., Mark, D. and Harrison, R. M. (2000), Indoor/outdoor relationships of particulate matter in domestic homes with roadside, urban and rural locations. Atmos. Environ. 34: 2603-2612.

Jo, W. K. and Song, K. B. (2001), Exposure to volatile organic compounds for individuals with occupations associated with potential exposure to motor vehicle exhaust and/or gasoline vapor emissions. Sci. Total Environ. 269: 25-27.

Joop, H. and Henk, W.A. (1995), The exposure of cyclists, car drivers and pedestrians to trafficrelated air pollutants. International Archives of Occupational and Environmental Health 67: 187193.

Kinney, P. and Ozkaynak, H. (1991), Associations of daily mortality and air pollution in Los Angeles country. Environ. Res. 54: 99-120.

Lee, S. C., Chiu, M. Y., Ho, K. F., Zou, S. C. and Wang, X. (2002), Volatile organic compounds (VOCs) in urban atmosphere of Hong Kong. Atmos. Environ. 48: 375-382.

Li, C. S. (1994), Relationship of indoor/outdoor inhalable and respirable particles in domestic environments. Sci. Total Environ. 151: 205 -211.

Lillquist, D. R. and Zeigle, K. L. (1998), Assessment of occupational methyl-tertiary butyl ether to petroleum refinery and transport loading rack facility employees. Appl. Occup. Environ. Hyg. 13: $53-57$. 
Monod, A., Sive, C.S., Avino, P., Chen, T., Blake, D. R. and Rowland, S. (2001), Monoaromatic compounds in ambient air of various sites: a focus on correlations between the xylenes and ethylbenzene. Atmos. Environ. 35: 135-149.

National Science and Technology Council, Interagency Assessment of Oxygenated Fuels, Committee on Environmental and Natural Resources, Executive Office of the President of the United States, June, 1997.

NIOSH. Recommendations for occupational safety and health Standards. DHHS (NIOSH) Publication No. 88-111. Cincinnati, OH: US Department of Health and Human Services, Public Health Service, Centers for Disease Control, National Institute for Occupational Safety and Health, 1988.

NIOSH/OSHA/DOE. http://www.osha-slc.gov /SLTC /healthguidelines /index.html. Revision date: February 17th, 2000.

Pohl, H. R., Roney, N., Wilbur, S., Hansen, H., De, R. and Christopher, T. (2003), Six interaction profiles for simple mixtures. Chemosphere 53: 183-197.

Romieu, I., Meneses, F. and Ruiz, S. (1996), Effects of air pollution on the respiratory health of asthmatic children living in Mexico City. Am. J. Resp. Crit. Care Med. 154: 300-307.

Sigsby, J. E., Tejada, S. and Ray, W. (1987), Volatile organic compound emissions from 46 in-use passenger cars. Environ. Sci. Technol. 21: 466-475.

Tsai, P. J., Lee, C. C., Chen, M. R., Shih, T. S., Lai, C. H. and Liou, S. H. (2002), Predicting the contents of BTEX and MTBE for the three types of tollbooth at a highway toll station via the direct and indirect approaches. Atmos. Environ. 36: 5961-5969.

U.S. Environmental Protection Agency (U.S. EPA), 1993. Assessment of potential health risks of gasoline oxygenated with methyl tertiary butyl ether (MTBE), EPA/600/R-93/206, Office of Research and Development, U.S. Environmental Protection Agency, Washington DC.

Vainiotalo, S., Peltonen, Y. and Pfäffli, P. (1998), MTBE concentrations in ambient air in the vicinity of service stations. Atmos. Environ. 32, 3503-3509.

Vainiotalo, S., Peltonen, Y. and Ruonakangas, A. (1999a), Customer exposure to MTBE, TAME,C6 alkyl methyl ethers, and benzene during gasoline refueling. Environ. Health Persp. 107: 133-140.

Vainiotalo, S. and Ruonakangas, A. (1999b), Tank truck driver exposure to vapors from oxygenated or reformulated gasolines during loading and unloading. Am. Ind. Hyg. Assoc. J. 60: 518-525. 